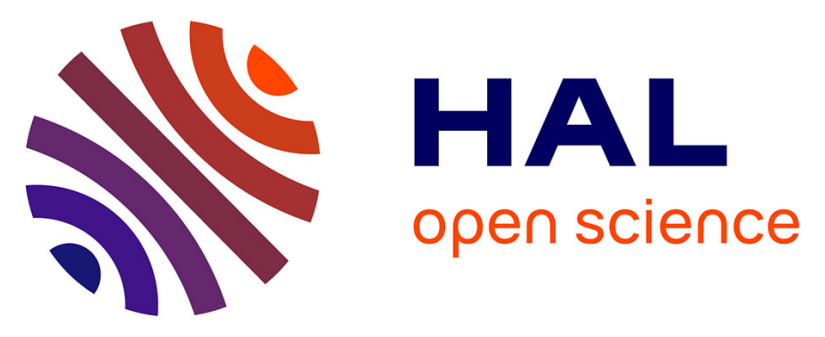

\title{
1H-NMR metabolomics: Profiling method for a rapid and efficient screening of transgenic plants
}

Yosra Ben Akal-Ben Fatma, Katia Pianelli, Martine Dieuaide Noubhani, Aline

Le Menn, Catherine C. Deborde, Mickael M. Maucourt, Marie-Hélène

Andrieu, Dominique D. Rolin, Christophe Rothan, Annick Moing, et al.

\section{To cite this version:}

Yosra Ben Akal-Ben Fatma, Katia Pianelli, Martine Dieuaide Noubhani, Aline Le Menn, Catherine C. Deborde, et al.. 1H-NMR metabolomics: Profiling method for a rapid and efficient screening of transgenic plants. African Journal of Biotechnology, 2012, 11 (52), pp.11386-11399. 10.5897/AJB12.088 . hal-02643145

\section{HAL Id: hal-02643145 \\ https://hal.inrae.fr/hal-02643145}

Submitted on 28 May 2020

HAL is a multi-disciplinary open access archive for the deposit and dissemination of scientific research documents, whether they are published or not. The documents may come from teaching and research institutions in France or abroad, or from public or private research centers.
L'archive ouverte pluridisciplinaire HAL, est destinée au dépôt et à la diffusion de documents scientifiques de niveau recherche, publiés ou non, émanant des établissements d'enseignement et de recherche français ou étrangers, des laboratoires publics ou privés. 


\title{
${ }^{1} \mathrm{H}-\mathrm{NMR}$ metabolomics: Profiling method for a rapid and efficient screening of transgenic plants
}

\author{
Yosra Ben Akal-Ben Fatma ${ }^{1}$, Katia Pianelli ${ }^{2}$, Martine Dieuaide-Noubhani ${ }^{3}$, Aline Le Menn ${ }^{5}$, \\ Catherine Deborde ${ }^{2,4}$, Mickaël Maucourt ${ }^{3,4}$, Marie-Hélène Andrieu ${ }^{2}$, Dominique Rolin ${ }^{3,4}$, \\ Christophe Rothan ${ }^{2}$, Annick Moing ${ }^{2,4}$, Sadok Bouzid ${ }^{1}$ and Cécile Cabasson ${ }^{3,4 \star}$. \\ ${ }^{1}$ Laboratoire de Morphogenèse et Biotechnologies Végétales, Faculté des Sciences Mathématiques, Physiques et \\ Naturelles de Tunis, Campus Universitaire Tunis El Manar, 2092 Tunis, Tunisie. \\ ${ }^{2}$ INRA, UMR 1332 Biologie du Fruit et Pathologie, Centre INRA de Bordeaux, BP 81, F-33140 Villenave d'Ornon, \\ France. \\ ${ }^{3}$ Université de Bordeaux, UMR 1332 Biologie du Fruit et Pathologie, Centre INRA de Bordeaux, BP 81, F-33140 \\ Villenave d'Ornon, France. \\ ${ }^{4}$ Plateforme Métabolome-Fluxome - Centre de Génomique Fonctionnelle de Bordeaux, Centre INRA de Bordeaux, BP \\ 81, F-33140 Villenave d'Ornon, France. \\ ${ }^{5}$ UAPV Avignon, Laboratoire de Physiologie des Fruits et Légumes - EA4279, \\ Pôle Agrosciences, BP 21239, F-84000 Avignon, France.
}

Accepted 18 April, 2012

\begin{abstract}
Metabolomics-based approaches are methods of choice for studying changes in fruit composition induced by environmental or genetic modulation of biochemical pathways in the fruit. Owing to enzyme redundancy and high plasticity of the metabolic network, transgenic alteration of the activity of the enzymes from the central metabolism very often results in only slight modifications of the fruit composition. In order to avoid costly and time-consuming plant analysis, we used a fast and sensitive ${ }^{1} \mathrm{H}$-NMR-based metabolomic profiling technique allowing discovery of slight metabolite variations in a large number of samples. Here, we describe the screening of transgenic tomato plants in which two genes from the central metabolism, phosphoenolpyruvate carboxylase (EC.3.4.1.1) and malate synthase (EC 2.3.3.9) were silenced by antisens and RNAi strategy. ${ }^{1} \mathrm{H}-\mathrm{NMR}$ metabolomic profiles of methanol-d4 $\mathrm{D}_{2} \mathrm{O}$ buffer extracts of tomato fruit flesh were acquired and subjected to unsupervised multivariate statistical analysis. ${ }^{1} \mathrm{H}-\mathrm{NMR}$ spectra were binned into variable-size spectral domains, making it possible to get an overall analysis of a large number of resonances, even in the case of uncontrolled variation of the chemical shift. Principal component analysis was used to separate groups of samples and to relate known and unknown metabolites to transgenic events. The screening of 100 samples, from extraction to data mining, took $36 \mathrm{~h}$. Thus, this procedure allows the rapid selection of metabolic phenotypes of interest among about 30 transgenic lines.
\end{abstract}

Key words: Metabolome, GMO, tomato, fruit, ${ }^{1} \mathrm{H}-\mathrm{NMR}$ profiling, screening.

\section{INTRODUCTION}

Metabolic profiling of plants displaying genetic variability, either natural or induced via mutagenesis or genetic transformation, is an efficient strategy for discovering new

\footnotetext{
*Corresponding author. E-mail: Cecile.Cabasson@bordeaux.inra.fr. Tel: +33(0)5 57122528. Fax: +33(0)5 57122541 .
}

enzymatic functions, biochemical pathways or metabolic connections (Moing et al., 2004; Rothan and Causse, 2007; Fernie and Klee, 2011). Besides the use of natural genetic variability, which resulted in considerable advances in fruit biology (White, 2002), combined use of transgenesis and metabolomics has recently emerged as a powerful method for our further understanding of tomato fruit metabolism and its relationship with fruit 
development and quality (Gilbert et al., 2009; Enfissi et al., 2010; Centeno et al., 2011; Dal Cin et al., 2011). However, the production of transgenic plants suitable for rigorous plant physiology studies requires several timeconsuming steps including the initial transformation, the selection of single-gene insertion diploid lines and, finally, the choice of a limited number of transgenic plants displaying a range of phenotypic alterations. To study fruit composition and identify altered metabolites and/or pathways, metabolomics screening of a large number of plants is often required. While targeted analysis is timeconsuming and too restrictive, untargeted analyses allow detection of unintended effects, it should be preferred as first step (Sumner et al., 2003).

Over the last decade, the development of tools in metabolomics has allowed non-selective analyses of a broad range of metabolites $(<3 \mathrm{kDa})$. These analyses based on nuclear magnetic resonance spectroscopy (NMR) or mass spectrometry (MS) detection, hyphenated or not with chromatography separation, allow the detection of metabolite features and identified metabolites from biofluids, whole organism, tissue or cell extracts (Fernie et al., 2004). They are used to study the responses of cells, tissues or organs to metabolic perturbations in medical research (Lindon and Nicholson, 2008), food science (Sobolev et al., 2003), nutrition and quality (Hall et al., 2008), GMO crops (Le Gall et al., 2003), medicinal plants (Choi et al., 2004; Hagel et al. 2008), and plant functional genomics (Roessner et al., 2001; Hagel and Facchini, 2008; Mounet et al., 2009; Saito and Matsuda, 2010). ${ }^{1} \mathrm{H}-\mathrm{NMR}$ is a fast, robust and highly reproducible quantitative method for the analysis of large number of metabolites in plant extracts (Sobolev et al., 2005; Hagel et al., 2008; Ward et al., 2010; Kim et al., 2010). Nevertheless, plant extracts preparation protocols should be chosen with care depending on whether the quantitative or qualitative extraction of metabolites is required (Ryan and Robards, 2006). With the former consideration and with special care for NMR acquisition parameters (Allwood et al., 2011), quantitative ${ }^{1} \mathrm{H}-\mathrm{NMR}$ allows the simultaneous detection and absolute quantification of about 30 to 40 metabolites within a single analysis (Moing et al., 2004). In contrast, plant extract preparation protocols are less demanding in terms of metabolite recovery for ${ }^{1} \mathrm{H}$-NMR metabolomics fingerprinting, which is very well-suited for rapid screening of biological samples (Le Gall et al., 2003; Ward et al., 2010). Moreover, ${ }^{1} \mathrm{H}-\mathrm{NMR}$ metabolomics fingerprinting allows relative quantitative comparison of spectra in the same series. Such information is especially relevant when analyzing transgenic plants displaying alterations in plant central metabolism, in which slight quantitative variation rather than presence/absence of primary metabolites are expected.

In this study, we report the development of a ${ }^{1} \mathrm{H}-\mathrm{NMR}$ metabolic profiling method fast enough to be used for rapid screening of transgenic plants from the T0 generation. As a proof-of-concept, we analyzed transgenic tomato plants silenced for Slppc2, a fruit specific phosphoenolpyruvate carboxylase (Guillet et al., 2002) and for malate synthase (Graham et al., 1994), two genes encoding enzymes of central metabolism with putatives roles in organic biosynthesis in the fruit. We demonstrated that the procedure designed allows the detection and relative quantification of all major metabolic compounds in the fruit (sugars, organic acids and amino acids); information provides plant central metabolism understanding; results can be stored in a standardized manner thus allowing comparison with other data; this method is simple, fast and cheap.

\section{MATERIALS AND METHODS}

\section{Plant material and genetic transformation}

The tomato (Solanum lycopersicum L.) fruit-specific Slppc2 phosphoeno/pyruvate carboxylase gene (Solgen SGN-U314026) was silenced using an antisens (AS) strategy. A 192 bp Slppc2 DNA fragment located in the 3'UTR region was PCR-amplified using specific primers (F-5'TGGTTAAATCTATTAC3'; R-5'GGTAAATGAAGAGAAG3') and cloned into the pBI121 vector as an inverted repeat under the control of the $35 \mathrm{~S}$ promoter. Following genetic transformation of tomato (cv. Ferum) via Agrobacterium tumefaciens strain LB A44104 according to Hamza and Chupeau (1993), the independent primary transgenic plants (T0) were further checked for ploidy level and gene insertion number. For this study, 6 single-insertion diploid T0 plants $\left(\mathrm{P}_{355}:\right.$ SIPPC $\left.^{\mathrm{AS}}\right)$ were selected.

Following T0 selfing and kanamycin selection of transgenic T1 seedlings, the homozygous T1 plants were detected by PCR and southern analysis and grown in insect-proof greenhouse under standard conditions. For each line, 2 to $4 \mathrm{~T} 1$ homozygous transgenic plants were analysed.

The tomato SIMLS malate synthase gene (Solgen SGNU573204) was silenced using a RNAi strategy. A 247 bp MLs DNA fragment located in the coding region of the unigene malate synthase like was PCR-amplified using specific primers ( $F-5$, TTC ACC AAG CTG GGA GAA TTT 3'; R- 5'GTT GAT ACG GTT GAA AGC GTT 3'). The purified DNA fragment was cloned as an inverted repeat under the control of the $35 \mathrm{~S}$ promoter using the Gateway cloning system, first into the entry vector pDONR 201, then into the destination vector pK7GWIWG2. Tomato transformation and transgenic plant selection were done as described above except that the cultivar "Ailsa Craig" and A. tumefaciens strain GV3101 were used. For this study, 7 singleinsertion diploid T0 plants $\left(\mathrm{P}_{35 \mathrm{~s}}: S I M L S^{\mathrm{RNAi}}\right)$ were analyzed. Wildtype and 6 independent lines transformed with an empty vector with the same protocol were used as control.

For metabolic profiling, one fruit per plant was harvested for $\mathrm{P}_{35 \mathrm{~s}}:$ SIPPC2 ${ }^{\mathrm{AS}}$ and 3 fruits per plant for $\mathrm{P}_{35 \mathrm{~s}}:$ SIMLS ${ }^{\mathrm{RNAi}}$ were harvested at red ripe stage from two to four plants per line (respectively T1 homozygous and T0 plants). Immediately following the harvest, deseeded fruits were cut into 4 parts and one quarter of the fruit, which constitutes one biological sample, was flashfrozen in liquid nitrogen, ground to a fine powder, lyophilised and stored at $-80^{\circ} \mathrm{C}$ until extraction.

\section{Chemicals}

Methanol- $d_{4}$ (99.8\%) and $\mathrm{D}_{2} \mathrm{O}$ (99.9\%) were purchased from Eurisotop (Gif sur Yvette, France). TSP (98\%) was purchased from Aldrich (Saint Quentin Fallavier, France). All the other chemicals 
were of reagent grade.

\section{Standard method for quantification of soluble metabolites}

The targeted analysis of the major sugars, organic and amino acids was performed using ethanolic extraction and a specific quantification method for each compound family. The extraction of soluble polar components was performed on $30 \mathrm{mg} \mathrm{DW}$ of tomato pericarp freeze-dried powder using series of hot ethanol/water extractions (successively $80 \%$ and $50 \%$ ), modified from Stitt and ap Rees (1978). The ethanolic extract was evaporated and solubilised in $1 \mathrm{ml}$ pure water. Glucose and fructose were determined on these extracts enzymatically at $340 \mathrm{~nm}$ using a microplate spectrophotometer (MR 5000, Dynatech, and St Cloud, France) on fruit samples (Kunst et al., 1984; Velterop and Vos, 2001). Malate and citrate were determined on these extracts by anion exchange HPLC (Dionex, Voisins le Bretonneux, France) with conductivity detection on fruit samples (Moing et al., 1998). Free amino acids were analyzed by HPLC on fruit samples, without sample purification, using the AccQ.Tag method from Waters (Milford, MA) with fluorescence detection (Cohen and Michaud, 1993).

\section{Methanol- $d_{4}$ extraction method of polar metabolites}

The extraction of the soluble components was performed as described by Le Gall et al. (2003) with the following modifications. The freeze-dried powder (50 mg DW) was mixed with $840 \mu \mathrm{L}$ of Methanol- $d_{4}$, and immediately added with $360 \mu \mathrm{L}$ of buffer solution (300 mM K $\mathrm{HPO}_{4} / \mathrm{KH}_{2} \mathrm{PO}_{4}, 2 \mathrm{mM}$ EDTA $\mathrm{Na}_{2}$ in $\mathrm{D}_{2} \mathrm{O}$ ). The mixture was vortexed $30 \mathrm{~s}$, stirred at $160 \mathrm{rpm}$ for $30 \mathrm{~min}$ at $20^{\circ} \mathrm{C}$ in an orbital incubator, then centrifuged at $3000 \mathrm{~g}$ for $10 \mathrm{~min}$ at $4^{\circ} \mathrm{C}$. The supernatant was collected and the pellet was extracted again with $360 \mu \mathrm{l}$ buffer solution. For the $\mathrm{P}_{35 \mathrm{~s}}$ :SIPPC2 ${ }^{\mathrm{AS}}$

sample set, the first supernatant $(500 \mu \mathrm{L})$ and the second one $(150$ $\mu \mathrm{L})$ were pooled in a glass tube, each sample consisting of a Methanol- $d_{4}$ : buffer solution $(54: 46, \mathrm{v} / \mathrm{v})$. For the $\mathrm{P}_{35 \mathrm{~s}}: S I M L S^{\mathrm{RNAi}}$ sample set, the first supernatant $(523 \mu \mathrm{L})$ and the second one $(65$ $\mu \mathrm{L}$ ) were pooled in an eppendorf tube. Each extract consisted of a methanol- $d_{4}$ : buffer solution $(62: 38, \mathrm{v} / \mathrm{v})$. Extraction in plastic container like eppendorf increases the risk to have impurities (like plasticizer) in extract but prevents the solvent volatility. In order to verify the absence of impurities, solvent blanks were systematically applied by running the extraction method with each experiment.

Sodium salt of (Trimethylsilyl) propionic-2, 2, 3, 3- $d_{4}$ acid (TSP) was added in the extract to a final concentration of $0.01 \%$ for chemical shift calibration. After centrifugation of the mixture at $10,000 \mathrm{~g}$ for $5 \mathrm{~min}$ at $20^{\circ} \mathrm{C}$ to eliminate traces of insoluble material, $500 \mu \mathrm{L}$ of the resulting supernatant were transferred into a $5 \mathrm{~mm}$ NMR tube for immediate acquisition.

\section{${ }^{1} \mathrm{H}-\mathrm{NMR}$ spectra acquisition}

${ }^{1} \mathrm{H}-\mathrm{NMR}$ spectra (1D) were recorded at $500.162 \mathrm{MHz}$ on a Bruker Avance spectrometer using a $5 \mathrm{~mm}$ Broad Band Inverse probe. In order to suppress the water signal, spectra were acquired with the pulse sequence based on the nuclear Overhauser effect known as noesy-presat (NOESYGPPR1D in Bruker library): $\mathrm{RD}-90^{\circ}-\mathrm{t} 1-$ $90^{\circ}-\mathrm{tm}-90^{\circ}$ - collect FID, where RD is a relaxation delay (respectively $10 \mathrm{~s}$ and $3 \mathrm{~s}$ for the $\mathrm{P}_{35 \mathrm{~s}}$ : SIMLS ${ }^{\mathrm{RNAi}}$ and the P35S: SIPPC2 ${ }^{A S}$ samples), during which the water is selectively irradiated, t1 represents the first increment in a NOESY experiment and was set to $4 \mu \mathrm{s}$; and the mixing time tm had a value of $100 \mathrm{~ms}$, during which the water resonance was again selectively irradiated. 32 and 64 scans were collected respectively for the $P_{35 s}$ :SIMLS ${ }^{\mathrm{RNAi}}$ and the $P_{355}: S I P P C 2^{A S}$ samples. The noesy-presat technique, with its highest chemical shift selectivity over the other presaturation ones, is the technique of choice for the high-quality and reproducibility acquisition of spectra of aqueous samples (Ross et al., 2007; Kim et al. 2010). An automation procedure (automatic shimming and automatic sample loading) requiring $15 \mathrm{~min}$ per sample was used for acquisition.

\section{${ }^{1} \mathrm{H}-\mathrm{NMR}$ data processing and archiving}

A line broadening of $0.3 \mathrm{~Hz}$ was applied to the FID prior to Fourier transformation. Phase and baseline correction were manually done by using TOPSPIN v1.3 software (Bruker). ${ }^{1} \mathrm{H}$ chemical shifts were referenced to the internal chemical shift reference TSP at $0.00 \mathrm{ppm}$.

The assignments of metabolites in the ${ }^{1} \mathrm{H}$-NMR spectra were made by comparing the proton chemical shifts with literature values obtained in similar solvent condition (Le Gall et al., 2003), with metabolomic profiles (MeRy-B data base, http://www.cbib.ubordeaux2.fr/MERYB/; Riken Standard Spectrum search, http://prime.psc.riken.jp/), by comparison with spectra of authentic compounds recorded under the same solvent conditions in methanol-d4 (own local database) and by spiking the samples when the pure compound was available in chemical library public or commercial.

The procedure of analysis of the one-dimensional (1D) ${ }^{1} \mathrm{H}-\mathrm{NMR}$ spectra, included spectral binning or bucketing, using AMIX software v3.8.10 (Bruker) in the variable size bucketing mode, that is each bucket may have an individual size. This technique partitions a 1D spectrum into small spectral regions (buckets) and integrates each of them. Then, the definition of a spectral pattern (that is a group of resonance areas in 1D-NMR spectra) was refined graphically on the basis of assignments previously discussed. Whenever possible, buckets were focused on signal regions of identified known and unknown metabolites and on non-identified signal regions, showing no overlap with neighbouring signals. Otherwise, they were aggregated to avoid splitting of a single peak. If necessary, several unrelated peaks showing substantial shift variation of the proton chemical shifts were also compiled into broader buckets (bucket $n^{\circ} 5$ Figure 1). Bucketed data were created, resulting in 94 variables for the 16 samples $\mathrm{P}_{35 \mathrm{~s}}$ :SIPPC2 ${ }^{\mathrm{AS}}$ set and 71 variables for the 40 samples P35S: SIMLS ${ }^{\mathrm{RNAi}}$ set.

In order to compare the area of the buckets, as buckets had different sizes, the integrals per bucket were divided by the number of data points. Moreover, all integration values were scaled to total intensity that is divided by the total intensity of the spectrum (with removal of the internal standard, residual water and methanol regions). The bucketed data table was written as a text file that could be used as input for further statistical analysis (Holmes et al., 1994). The data processing time necessary to define the bucket pattern that depends on the knowledge of the biological material composition was about 30 min here for pericarp of red tomato fruit. For archiving and further data mining, the ${ }^{1} \mathrm{H}$-NMR spectra of all samples were converted into JCAMP-DX format and deposited, with associated metadata, into the Metabolomics Repository of Bordeaux MeRy-B (Ferry-Dumazet et al., 2011; http://www.cbib.ubordeaux2.fr/MERYB/res/project/T06005).

\section{Multivariate and univariate analyses}

To get an overview of the each data set and highlight discriminant spectra region, after a bucket table had been calculated or loaded,multivariate analysis was performed using AMIX software v3.9.10 (Bruker) using principal component analysis (PCA). In order 


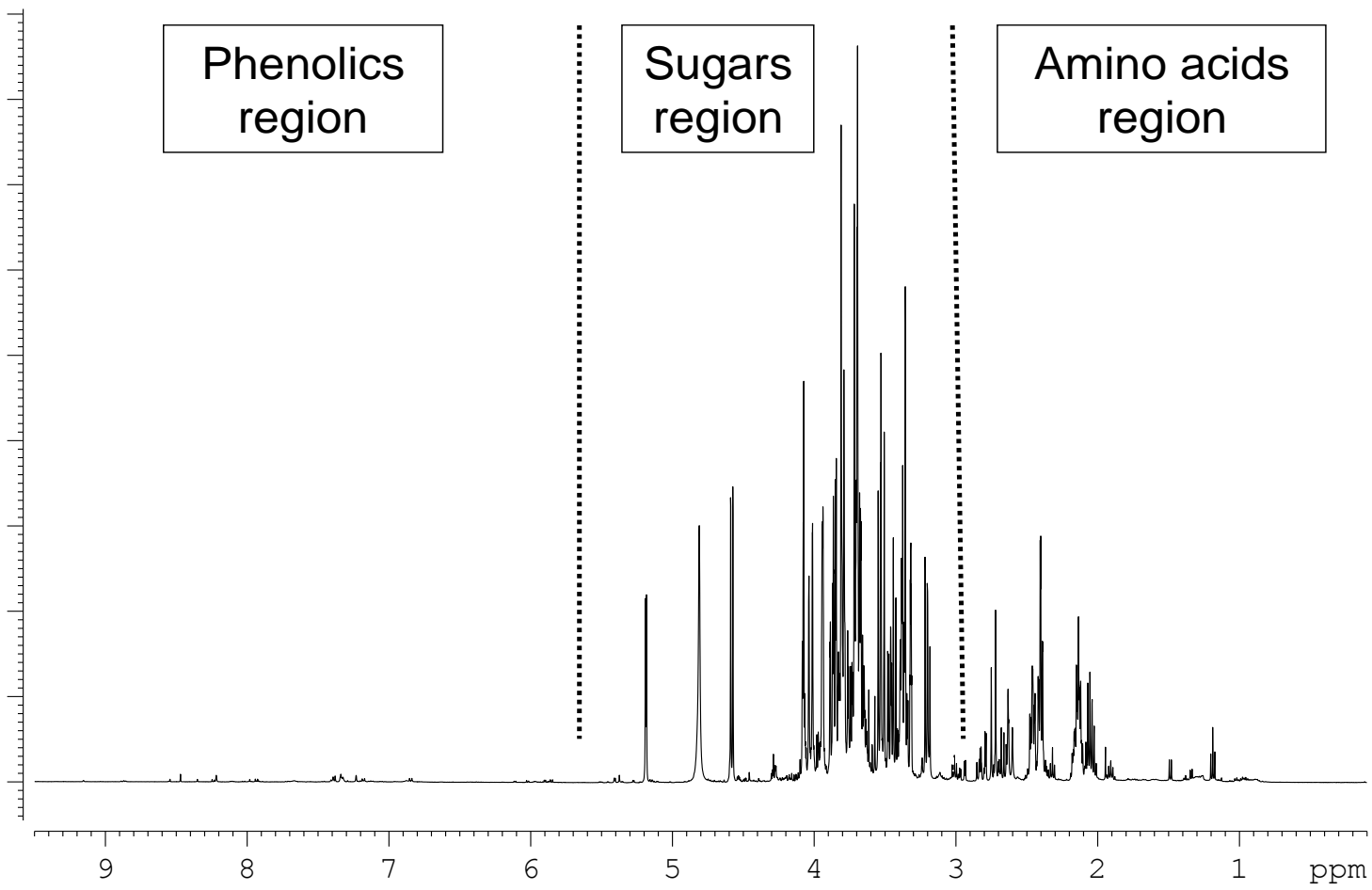

Amino acids region

b65 b67 b69

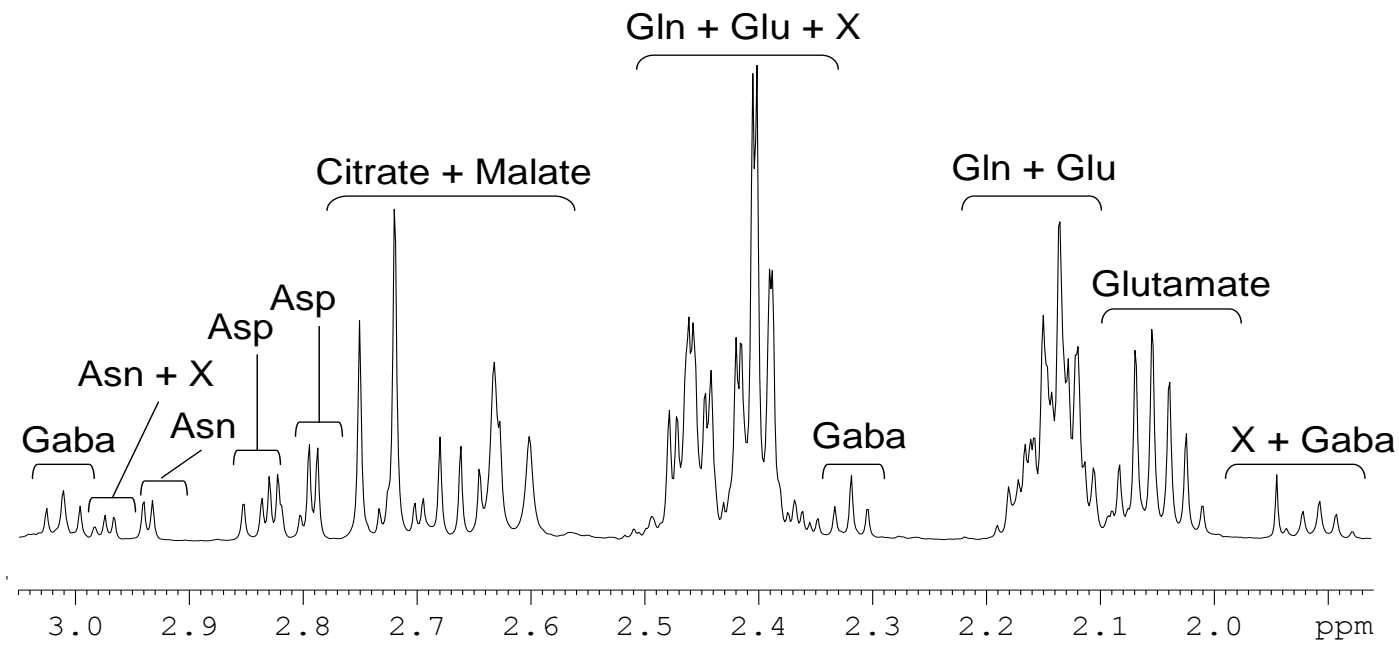

Figure 1. Examples of portions of a ${ }^{1} \mathrm{H}-\mathrm{NMR}$ spectra of red tomato fruit extract from a representative $\mathrm{P}_{35}: \mathrm{SIPPC}^{\mathrm{AS}}$ transgenic plant. The spectral region, with proton resonances corresponds to: Phenolics region (9.2-5.5 ppm); sugars region (5.5-3 ppm); amino acids region (3-0.8 ppm). Resonances are annotated according to Table 1. Bucket positions are indicated by bars (asn, asparagine; asp, aspartic acid; glu, glutamic acid; gln, glutamine; phe, phenylalanine; pyroglu, pyroglutamic acid; suc, sucrose; trigo, trigonelline; tyr, tyrosine; $\mathrm{X}$, unknown metabolite). 


\section{Sugars region}
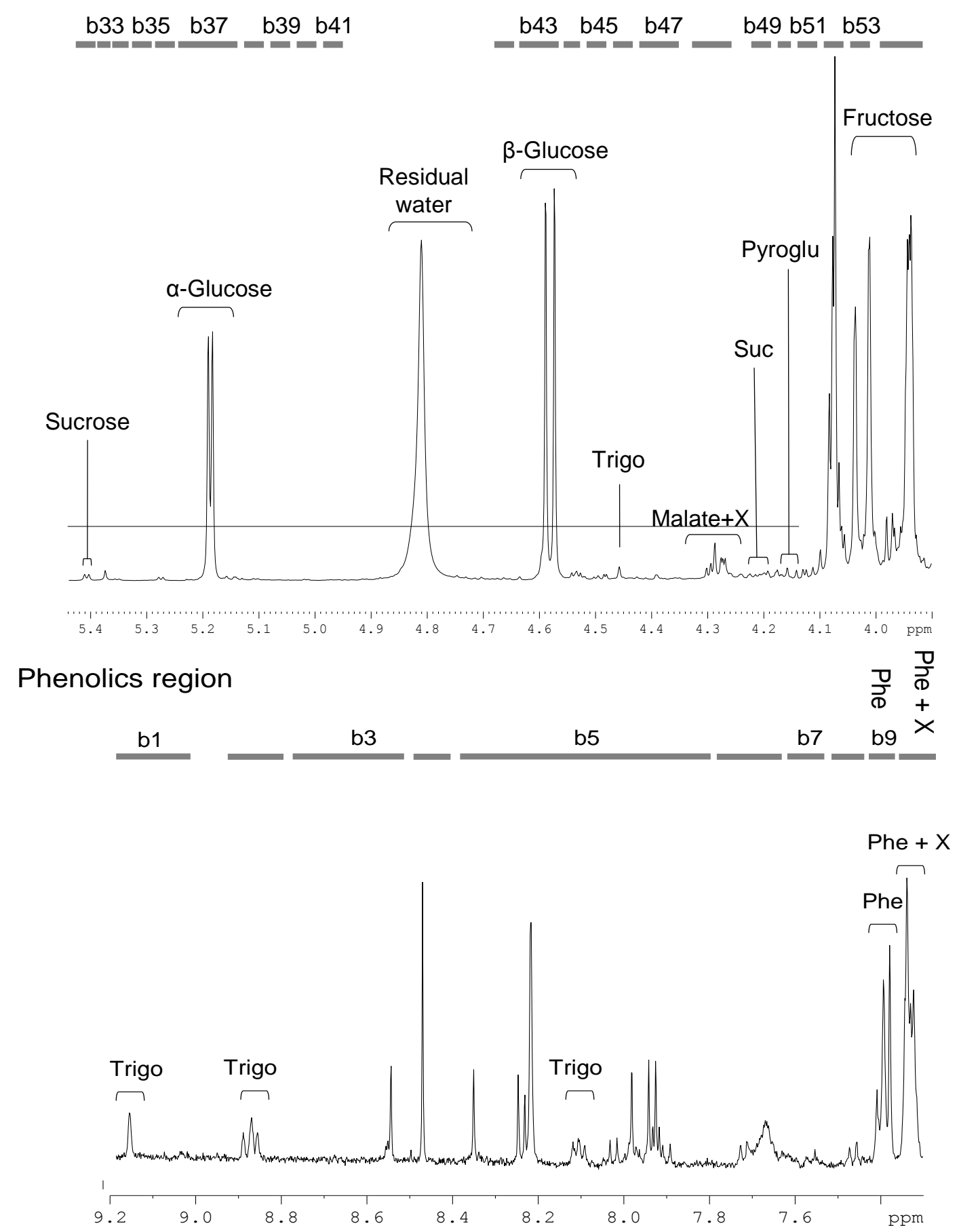

Figure 1. Contd.

to minimize the influence of baseline deviations and noise, all variables (bucket table columns) were normalized by scaling to unit variance in order to limit the influence of the major sugars. Multivariate techniques such as PCA are routinely used to identify groupings, trends, and outliers within NMR data sets (Trygg et al., 2007). The interpretation of PC loadings has already been well described (Defernez and Colquhoun, 2003). Analysis of variance (ANOVA) using SAS software was used to compare the means of the 94 buckets in 16 samples for the P35S: SIPPC2 ${ }^{A S}$ set and 71 buckets in 40 samples for the $P_{35 s}: S I M L S^{\text {RNAi }}$ set. Pearson correlation coefficients were used to compare ${ }^{1} \mathrm{H}-\mathrm{NMR}$ relative quantification data and targeted absolute quantification data from 
HPLC or enzymatic methods.

\section{RESULTS AND DISCUSSION}

\section{The tomato SIppc2 and SIMLs genes encode enzymes of central metabolism}

Besides the small gene family encoding phosphoenolpyruvate carboxylase (PEPC) in tomato, the SIppc2 gene encodes a fruit-specific phosphoenolpyruvate carboxylase or PEPC (Guillet et al., 2002). One of the functions fulfilled by non-photosynthetic PEPCs is the replenishment of the tricarboxylic acid cycle (TCA cycle) with oxaloacetate by catalyzing the PEP to oxaloacetate conversion (Chollet et al., 1996; O'Leary et al., 2011). PEPC appears therefore as a key enzyme in the synthesis of malic and citric acids, the two major organic acids accumulated in tomato. A possible role of the Slppc2-mediated organic acid synthesis is to sustain osmotic potential to allow rapid fruit cell expansion (Guillet et al., 2002; O'Leary et al., 2011).

The occurrence of malate synthase (MLs) was also investigated by Nieri at al. (1997) in different tissues of tomato plants (leaves, fruits, roots and flowers). In banana, $M L s$ gene was expressed specifically in ripening fruit tissue and transcripts were not detected in the other organs (roots, leaves, ovary, male flower...) and in fruit at different stages of development (Pua et al., 2003). Malate synthase is responsible for malic acid synthesis in the glyoxylate cycle, whose function is to convert stored lipids to carbohydrates by catalysing the glyoxylate condensation reaction with acetyl-CoA in the peroxisome (Cornah et al., 2004). The glyoxylate cycle plays an anaplerotic role to replenish the intermediates, for example succinate, of the TCA cycle, which is the major cellular machinery for oxidative metabolism and energy production (Graham et al., 1994; Eastmond and Graham, 2001). The functional glyoxylate cycle may therefore play an anaplerotic and gluconeogenetic role responsible for the accumulation of sugars and organic acids in the fruit.

Silencing the SIppc2 encoding PEP carboxylase or the SIMLs encoding malate synthase in tomato by antisens or RNAi strategy may therefore result in alterations in fruit composition, especially in sugar and organic acid contents. Besides the characterization of transgenic lines at the molecular level (the measurement of Slppc2 and SIMLs transcript abundance) and by visual phenotypic characterization (their fruit size or shape), their metabolomics characterization through a fast and discriminating method appears as a prerequisite for further understanding of the functional role of SIppc2 and SIMLs in the fruit.

\section{Estimation of the variation of metabolite levels from ${ }^{1} \mathrm{H}$-NMR spectra of methanol- $d_{4}$ extract of tomato fruit: Validation by quantitative methods}

In the past, our laboratory tested and validated a metabolic profiling method by $1 \mathrm{D}{ }^{1} \mathrm{H}-\mathrm{NMR}$ where soluble sugars, organic acids, amino acids and some secondary metabolites of plant organs were extracted with ethanol/ water series to allow absolute quantification (Moing et al., 2004). The major benefits of this protocol where ${ }^{1} \mathrm{H}-\mathrm{NMR}$ absolute quantification is performed with a synthesic electronic reference signal, were high correlations between ${ }^{1} \mathrm{H}$-NMR data and enzymatic or HPLC data. However, this protocol requires a lot of time to prepare extracts (four days). Here, our aim was to test a new protocol with shorter time to prepare plant extracts and allow plant screening at biochemical level. Generally, a wide range of primary metabolites (except lipids) in any type of biological material is hydrophilic. Thus, a methanolic extraction protocol is commonly used to extract plant metabolites (Le Gall et al., 2003; Gromova and Roby, 2010). The use of deuterated solvent spares time by avoiding the step of extract lyophilization and thus simplifies and speeds up the extract preparation process. Figure 1 shows a representative $\mathrm{H}-\mathrm{NMR}$ spectrum from methanol- $d_{4}$ : buffered solution extract of red tomato fruit from $\mathrm{P}_{355}$ :SIPPC2 ${ }^{\mathrm{AS}}$ transgenic plants. For the bucket integration, the exploited region comprised between 9.2 and $0.8 \mathrm{ppm}$, which corresponds to the phenolic/aromatic region (9.2-5.5 ppm), the sugar region (5.5-3 ppm) and the amino acid region (3-0.8 ppm). This region was partitioned into 94 variable-size buckets in order to fit to known metabolite signals. For citrate, glutamate and glutamine, signals were compiled into broader buckets to take into account limited uncontrolled variations of chemical shifts related to the composition of the complex extract $(\mathrm{pH}$, ionic force, and metal composition). 31 buckets were assigned to known metabolites including 21 buckets with resonance allowing the identification of three sugars, 14 amino acids, and three organic acids including citrate and malate and one quaternary amine (Table 1 ).

In our experimental procedure designed to allow a rapid analysis of plant tissue composition, a double methanol- $d_{4}$ extraction followed by ${ }^{1} \mathrm{H}-\mathrm{NMR}$ analysis and data reduction using bucketing were performed. In order to validate this protocol, we checked if the relative changes of selected ${ }^{1} \mathrm{H}$-NMR bucket spectra regions (normalized to total intensity) could be quantitatively related to metabolite absolute concentration measured with targeted methods on ethanolic extract on the same samples. For this purpose, the contents of major primary metabolites in tomato fruit were determined by standard quantitative methods such as enzymatically for fructose and glucose, by anion exchange HPLC coupled with conductivity detection for malate and citrate and by cation exchange HPLC coupled with fluorescence detection for amino acids (Table 2) for the $\mathrm{P}_{35 \mathrm{~s}}$ :SIPPC2 ${ }^{\mathrm{AS}}$ set. Glucose and fructose concentrations ranged from 790 to 1083 and 1014 to 1213 umole.g-1 DW, respectively. The malate and citrate concentrations ranged from 49 to 81 and 183 to $293 \mu$ mole.g-1 DW respectively. The individual amino acid concentrations ranged from 8 to 
Table 1. Buckets containing identified resonance of compounds from 1-D ${ }^{1} \mathrm{H}-\mathrm{NMR}$ spectra of red tomato fruit extracts $\left(P_{35}:\right.$ SIPPC2 $\left.{ }^{A S}\right)$.

\begin{tabular}{|c|c|c|c|c|}
\hline Buckets $^{a}$ & Compounds & Groups & Multiplicity & Chemical shift $^{\mathrm{b}}$ (ppm) \\
\hline 1.51 & Alanine & $\mathrm{C}_{3} \mathrm{H}_{3}$ & $d$ & 1.48 \\
\hline $2.93 / 2.97$ & Asparagine & $\mathrm{C}_{3} \mathrm{H}_{2}$ & $\mathrm{~m}$ & 2.92 \\
\hline $2.80 / 2.84$ & Aspartate & $1 / 2\left(\mathrm{C}_{3} \mathrm{H}_{2}\right)$ & $\mathrm{m}$ & 2.81 \\
\hline 2.67 & Citrate(+malate) & $\mathrm{C}_{2} \mathrm{H}_{2}+\mathrm{C}_{4} \mathrm{H}_{2}$ & dd & 2.63 \\
\hline $4.08 / 4.02$ / 3.95 & Fructose & $\alpha(\mathrm{C} 3 \mathrm{H}+$ & $\mathrm{m}$ & 4.12 \\
\hline 3.02 / 2.32 / 1.93 & GABA & $\left.\mathrm{C}_{5} \mathrm{H}\right)+\beta \mathrm{C}_{5} \mathrm{H}$ & $\mathrm{t}$ & 3.01 \\
\hline 5.18 & Glucose & $\mathrm{C}_{4} \mathrm{H}_{2}$ & $d$ & 5.25 \\
\hline 4.59 & & $\mathrm{aC}_{1} \mathrm{H}$ & d & 4.66 \\
\hline $2.05 / 2.15$ & Glutamate & $\beta \mathrm{C}_{1} \mathrm{H}$ & $\mathrm{m}$ & 2.07 \\
\hline 2.15 & Glutamine & $\mathrm{C}_{3} \mathrm{H}_{2}$ & $\mathrm{~m}$ & 2.45 \\
\hline 0.98 & Isoleucine & $\mathrm{C}_{4} \mathrm{H}_{2}$ & $d$ & 1.01 \\
\hline 1.39 & Lactate & $\mathrm{C}_{6} \mathrm{H}_{3}$ & $d$ & 1.33 \\
\hline 0.89 & Leucine & $\mathrm{C}_{3} \mathrm{H}_{3}$ & $\mathrm{t}$ & 0.96 \\
\hline 1.79 & Lysine & $\mathrm{C}_{5} \mathrm{H}_{3}+\mathrm{C}_{6} \mathrm{H}_{3}$ & - & - \\
\hline 4.30 & Malate & - & dd & 4.30 \\
\hline 7.39 & Phenylalanine & $\mathrm{C}_{2} \mathrm{H}$ & $\mathrm{m}$ & 7.40 \\
\hline 4.17 & Pyroglutamate & $\mathrm{C}_{5} \mathrm{H}+\mathrm{C}_{6} \mathrm{H}+\mathrm{C}_{7} \mathrm{H}$ & dd & 4.18 \\
\hline $5.41 / 4.22$ & Sucrose & $\mathrm{C}_{2} \mathrm{H}$ & $\mathrm{d}$ & 5.41 \\
\hline 1.39 & Threonine & Glucopyranosyl- $C_{1}$ & d & 1.33 \\
\hline $9.15 / 4.65$ & Trigonelline & $\mathrm{C}_{4} \mathrm{H}_{3}$ & $s$ & 9.13 \\
\hline 7.34 & Tyrosine & $\mathrm{C}_{3} \mathrm{H}$ & d & 6.91 \\
\hline 1.04 & Valine & $\mathrm{C}_{6} \mathrm{H}_{2}$ & d & 1.04 \\
\hline & & $\mathrm{C}_{5} \mathrm{H}_{3}$ & & \\
\hline
\end{tabular}

${ }^{1} \mathrm{H}$ chemical shifts used for metabolite identification were determined at $\mathrm{pH} 6$ in $\mathrm{D}_{2} \mathrm{O}$ and were expressed as relative value to that of TSP at 0 ppm. Groups are indicated according to Fan (1996) and Le Gall et al. (2003). d, doublet; dd doublet of doublet; $\mathrm{m}$, multiplet; $\mathrm{s}$, singlet; $\mathrm{t}$, triplet. ${ }^{\mathrm{a}}$ Value corresponds to the middle of the bucket which has been focused on signal regions of identified metabolites described. Buckets indicated in italic are used for the correlation study. ${ }^{b}$ Chemical shift of pure compound in methanol- $d_{4}$.

Table 2. Concentration ( $\mu \mathrm{mol} . \mathrm{g}^{-1} \mathrm{DW}$ ) of ten metabolites quantified with standard quantification methods (hot ethanol/water extractions, HPLC-DA or enzymatic analyses) in pericarp extracts of red ripe tomato flesh from six $\mathrm{P}_{35}:$ SIPPC $^{\mathrm{AS}}$ lines.

\begin{tabular}{lllllll}
\hline Line & Ppc2_1 & Ppc2_2 & Ppc2_3 & Ppc2_4 & Ppc2_5 & Ppc2_6 \\
\hline Glucose & $840^{*}$ & $1030 \pm 26$ & $790 \pm 17$ & $1083 \pm 169$ & $935 \pm 105$ & $933 \pm 94$ \\
Fructose & $1053^{*}$ & $1185 \pm 69$ & $1014 \pm 53$ & $1213 \pm 165$ & $1142 \pm 71$ & $1073 \pm 104$ \\
Malate & $72^{*}$ & $57 \pm 10$ & $49 \pm 5$ & $74 \pm 22$ & Na & $81 \pm 20$ \\
Citrate & $213^{*}$ & $226 \pm 37$ & $183 \pm 18$ & $293 \pm 23$ & Na & $191 \pm 40$ \\
Glutamate & $147^{*}$ & $224 \pm 27$ & $296 \pm 54$ & $243 \pm 57$ & $235 \pm 28$ & $157 \pm 32$ \\
Glutamine & $87^{*}$ & $87 \pm 18$ & $132 \pm 38$ & $91 \pm 43$ & $148 \pm 18$ & $65 \pm 12$ \\
Aspartate & $73^{*}$ & $69 \pm 7$ & $103 \pm 17$ & $84 \pm 22$ & $79 \pm 14$ & $62 \pm 14$ \\
Asparagine & $40^{*}$ & $22 \pm 3$ & $43 \pm 10$ & $24 \pm 12$ & $38 \pm 6$ & $25 \pm 5$ \\
Alanine & $10^{*}$ & $9 \pm 0$ & $11 \pm 1$ & $8 \pm 2$ & $12 \pm 3$ & $9 \pm 1$ \\
GABA & $26^{*}$ & $35 \pm 5$ & $33 \pm 14$ & $23 \pm 1$ & $33 \pm 2$ & $27 \pm 7$ \\
\hline
\end{tabular}

Mean metabolite concentration ( $\left.\mu \mathrm{mol} . \mathrm{g}^{-1} \mathrm{DW}\right) \pm$ standard deviation with $\mathrm{n}=2$ to 3 ( $\mathrm{Na}$, data non determined; * one measurement).

296 umole.g-1 DW; the major amino acid being glutamate followed by glutamine, aspartate, asparagine and GABA. Then, we studied the relationship between the relative bucket areas (Figure 2) and the absolute amount of these seven major metabolites (Table 2) using correlation coefficients (Table 3). The linear correlation coefficients were significant $(P<0,05)$ for five compounds: superior to 0.9 for glucose, between 0.6 
A

\section{Sugars}

Fructose

Glucose $(\alpha+\beta)$

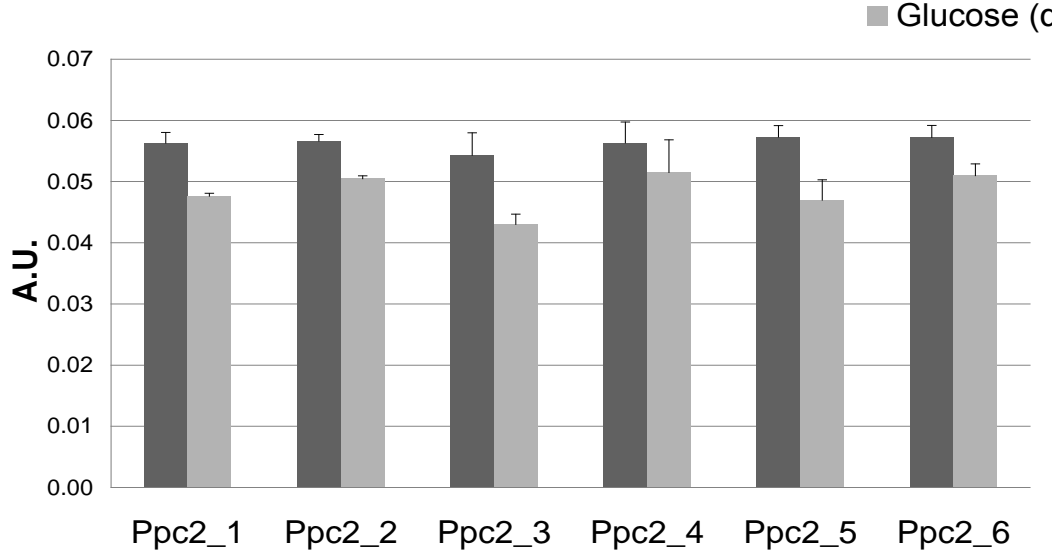

C

Malate

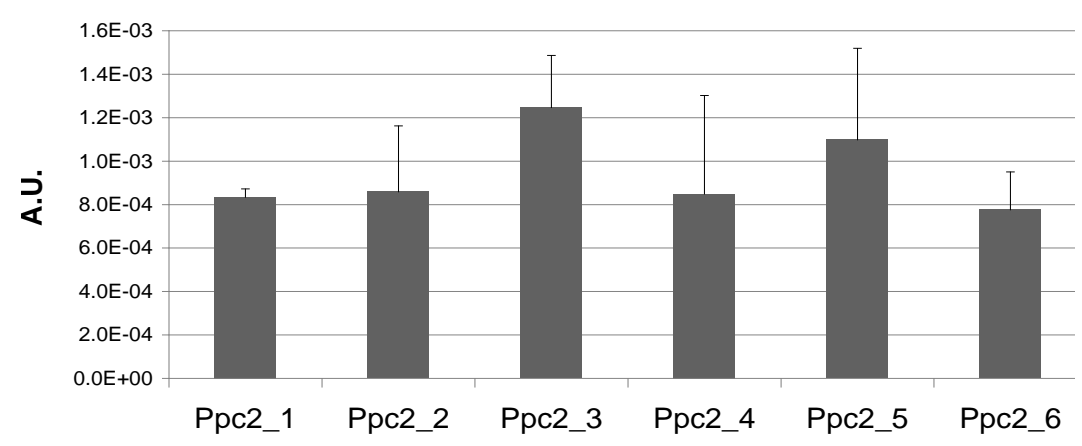

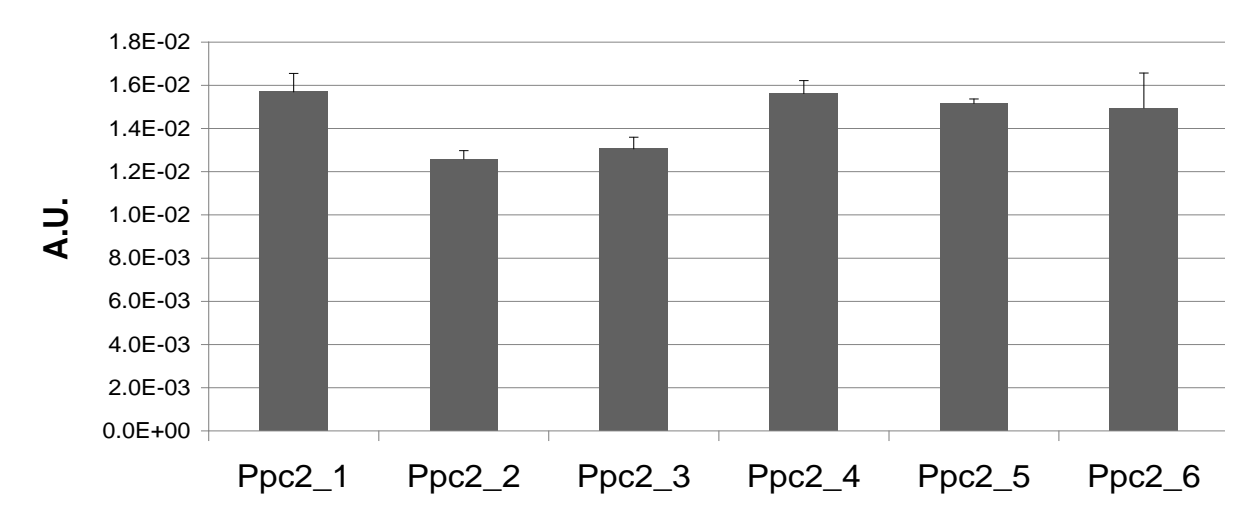

D

\section{Glutamate}

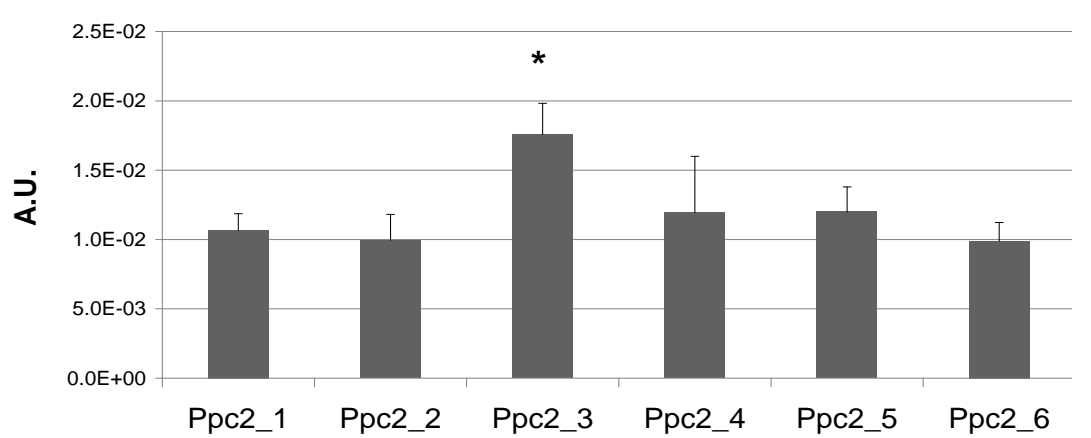

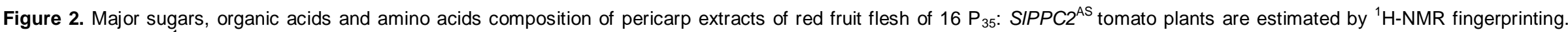
Values are given in ${ }^{1} \mathrm{H}-\mathrm{NMR}$ signal intensity in arbitrary unit (A.U.) as mean \pm standard deviation with $\mathrm{n}=2$ to 5 ( ${ }^{*}$ indicates significantly different at $P<0.05$ level).

and 0.8 for aspartate, asparagine and GABA. ${ }^{1} \mathrm{H}$ NMR relative bucket areas and HLPC absolute concentration data did not correlate significantly for malate and fructose. In a previous study using a single-step extraction of red tomato fruit with a mixture of $70 \%$ methanol- $d_{4} / 30 \%$ deutered solvent, the resonances corresponding to the malate were closed to the noise level (Le Gall et al., 2003). In our experiments, the malate signal 
E

\section{Asparagine}

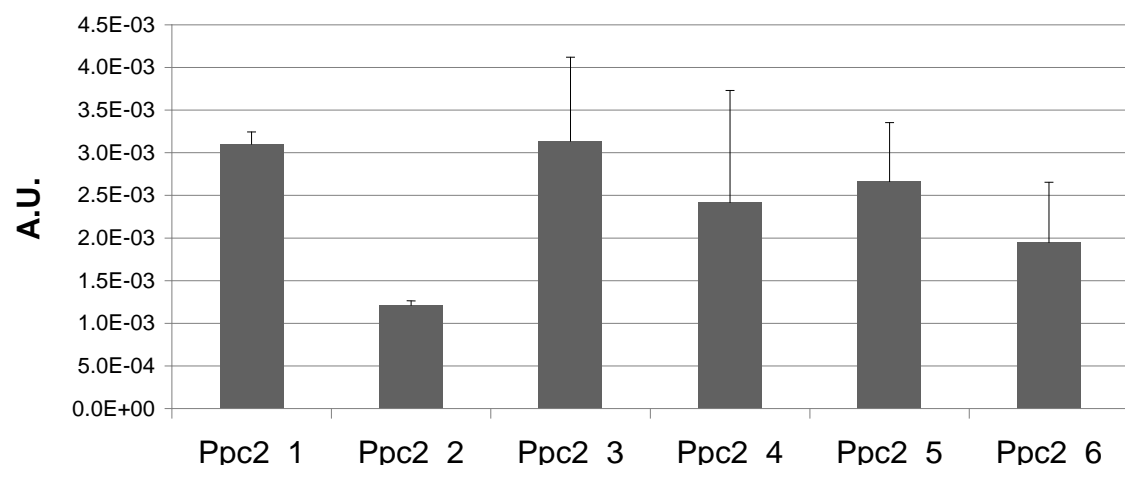

$\mathbf{F}$

Aspartate

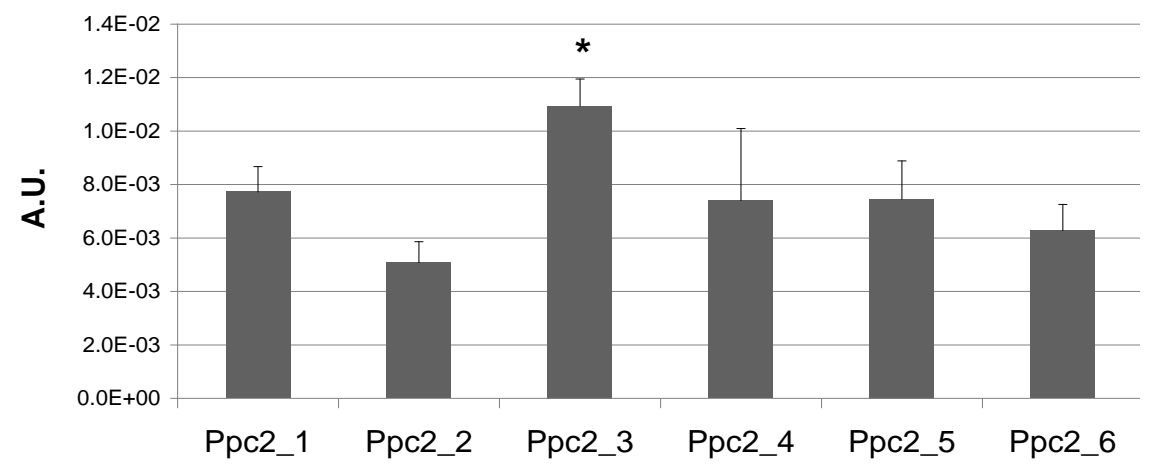

Figure 2. Contd.

Table 3. Correlation coefficients between relative bucket intensities calculated from ${ }^{1} \mathrm{H}-\mathrm{NMR}$ spectra and absolute concentrations calculated from enzymatic or HPLC analyses of red tomato fruit extracts from the $\mathrm{P}_{35 s}:$ SIPPC $^{\mathrm{AS}}$ transgenic plants.

\begin{tabular}{|c|c|c|c|c|c|c|c|}
\hline \multirow[b]{2}{*}{${ }^{1} \mathrm{H}$-NMR } & \multicolumn{7}{|c|}{ HPLC or enzymatic quantification } \\
\hline & Glucose & Fructose & Malate & Glutamate & GABA & Asparagine & Aspartate \\
\hline Glucose & $0.9^{*}$ & & & & & & \\
\hline Fructose & & 0.3 & & & & & \\
\hline Malate & & & 0.1 & & & & \\
\hline Glutamate & & & & $0.6^{*}$ & & & \\
\hline GABA & & & & & $0.7^{*}$ & & \\
\hline Asparagine & & & & & & $0.6^{*}$ & \\
\hline Aspartate & & & & & & & $0.8^{*}$ \\
\hline
\end{tabular}

Pearson correlations $(r)$ were calculated from 14 fruit samples for sugars, 11 fruit samples for organic acids and 15 fruit samples for amino acids. *indicates $P<0.05$.

was consequent certainly due to the addition of a second extraction step with buffer solution.

The absence of correlation between $1 \mathrm{H}$ NMR signal intensities and concentrations calculated from HPLC analyses is probably due to the long relaxation times of methyne and methylene groups of this compound (del Campo et al, 2006, reported $1.5 \mathrm{~s}$ for methyl group of malic acid in water at $\mathrm{pH} 1$ ), thus by using a relaxation delay of 
$3 \mathrm{~s}$ and an acquisition time of $2.72 \mathrm{~s}$ for the $P_{35 \mathrm{~s}}$ : SIPPC2 ${ }^{A S}$ samples, the total relaxation of the methylene group is not achieved (5.72 s< $5 \times 1.5 \mathrm{~s})$. Therefore, saturation of malic acid signals certainly occurred in our ${ }^{1} \mathrm{H}$-NMR conditions and limited the accuracy of malate quanti-fication with ${ }^{1} \mathrm{H}-\mathrm{NMR}$. Concerning fructose, quantification is difficult due to the presence of four isomeric forms and their resonances overlapping (Consonni et al., 2009). However, despite the lack of significant correlation, similar tendencies were revealed with the ${ }^{1} \mathrm{H}-\mathrm{NMR}$ procedure and the HPLC method: any significant variation of fructose between the different transgenic red tomato fruit extracts was noticed. Thus, these results show that the procedure that we described here, allowed a relative quantification of the major soluble metabolites in pericarp extracts of red tomato fruit.

\section{Multivariate analysis of ${ }^{1} \mathrm{H}-\mathrm{NMR}$ spectra for detection of alterations of metabolome in tomato associated with genetic transformation}

In this study, the transgenic line selection was performed among 16 plants (T1 generation) from 6 transgenic lines issued from independent transgenic events by using PCA data reduction technique on the fingerprints of tomato fruit extracts (Figure 3 and 4). For $\mathrm{P}_{355}:$ SIPPC2 ${ }^{A S}$ transgenic plants, an 8-component model accounted for $98 \%$ of total variability $(78 \%$ for the first three components). Examination of the scores plot (Figure 3A) allowed distinguishing three groups of transgenic lines (Ppc2_1, Ppc2_2 and Ppc2_3). The last ones were separated along the first principal component (PC1) explaining $56 \%$ of the total variability with Ppc2_2 on the positive side and Ppc2_3 on the negative side of PC1. Analysis of the loadings (Figure 3B) indicated that sugars but also amino acids and unknown metabolites contributed predominantly to this separation: glucose and unknown metabolites (3.45 and $3.81 \mathrm{ppm}$ buckets) on the positive side and amino acids (glutamate, aspartate, alanine, valine...) and unknown metabolites (6.79 and $6.96 \mathrm{ppm}$ buckets) on the negative side. We also noticed a considerable biochemical variation between plants from the same transgenic line (especially from Ppc2 4, Ppc2 5, and Ppc2 6) along PC1. Among the 94 studied variables from the ${ }^{1} \mathrm{H}$-NMR fingerprints of the corresponding pericarp deuterated extracts, the relative quantification of 14 identified individual polar compounds could be estimated (Figure 2). An analysis of variance was performed on the buckets corresponding to these 14 individual compounds to determine whether significant changes in levels of metabolites could be identified between the 16 fruit extracts. We noticed no significant modification of the soluble sugars levels (Figure $2 \mathrm{~A}$ ) and organic acids levels (Figure $2 \mathrm{~B}$ and $2 \mathrm{C}$ ) in the pericarp extracts of red tomato fruit. However, weak but significant modifications of glutamate (Figure 2D) and aspartate levels (Figure 2F) were observed $(P<0.05)$. Line Ppc2_3 exhibited higher levels than Ppc2_1 and Ppc2_2. In transgenic plants $\mathrm{P}_{355}$ :SIPPC2 ${ }^{\mathrm{AS}}$ (primary transgenic plants or T0 and T1 progeny), growth phenotype, fruit development and ripening were similar under greenhouse condition (data not shown). The maintenance of the plant growth was also observed in transgenic potato plant expressing antisens Solanum tuberosum ppc gene (Gehlen et al., 1996).

All studies on PEPC have established its fundamental role in the initial fixation of atmospheric $\mathrm{CO} 2$ during $\mathrm{C} 4$ and CAM photosynthesis in plant. However, PEPC also has diverse non-photosynthetic metabolic functions as recently reviewed (O'Leary, 2011), including for fruit development and ripening. A fruit-specific PEPC has been identified in tomato (Guillet et al., 2002) and has been physically and kinetically characterized in orange (Perotti et al., 2010). To our knowledge, our study is the first study of antisens plants for the fruit-specific PEPC. The genetic transformation resulted in weak but significantly changes of glutamate and aspartate levels between the transgenic lines. Amino acid levels were higher in the line Ppc2_3 and, the most affected. This result is in agreement with those obtained in ripening banana, suggesting that PEPC plays an anaplerotic role to replenish the TCA cycle carbon skeletons (Law and Plaxton 1997). Several attempts to overproduce PEPC in the leaves of C3 plants also showed an increase of anaplerotic provision of carbon skeletons for amino acids biosynthesis (Rademacher et al., 2002; Miyao and Fukayama, 2003). In siliques from Arabidopsis plants transformed with a Sorghum C4 PEPC, expressed under the constitutive control of the CaMV 35S promoter, Lebouteiller et al. (2007) noticed that a decrease in PEPC content and activity correlated with a decrease in glutamine level. The mechanisms apply to fruit-specific PEPC remain to be determined.

We were able to perform an early screening using ${ }^{1} \mathrm{H}$ NMR metabolomic profiles of methanol- $d_{4} \quad D_{2} \mathrm{O}$ buffer extracts of fruit. This allowed selecting three lines of $\mathrm{P}_{35 \mathrm{~s}}$ :SIPPC2 ${ }^{\mathrm{AS}}$ (Ppc2_1, Ppc2_2 and Ppc2_3) for further characterization, on the basis of their separation into three distinctive groups with PCA based on their amino acid levels and their lowest biological variability.

For $\mathrm{P}_{35 s}: S I M L S^{\mathrm{RNAi}}$ transgenic plants, the ${ }^{1} \mathrm{H}-\mathrm{NMR}$ spectra region between 9.20 and $1.05 \mathrm{ppm}$ of chemical shift was exploited and the experiment set contained 70 buckets including 22 buckets assigned to the resonance from a single metabolite, seven buckets with more than one metabolite assigned and 41 unknown ones. A 14component model accounted for $95 \%$ of total variability, with PC1 and PC2 explaining 25 and $18 \%$ of the variability, respectively. Examination of the scores plot (Fig 4) did not allow distinguishing any transgenic line different from the wild type. Rapidly, we have concluded that no individual of this experiment presented a biochemical phenotype significantly affected by the 


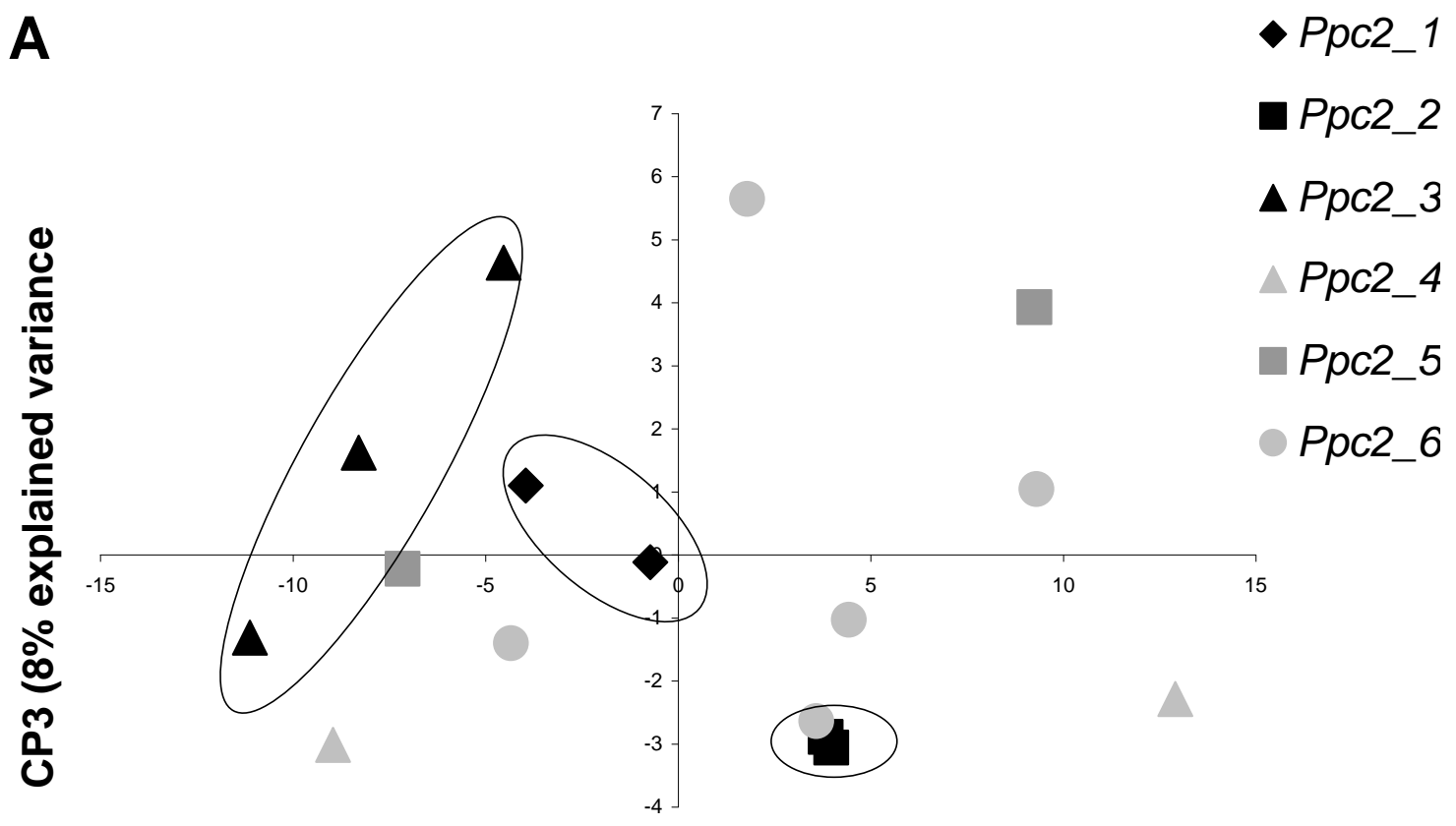

B

\section{CP1 (56\% explained variance)}

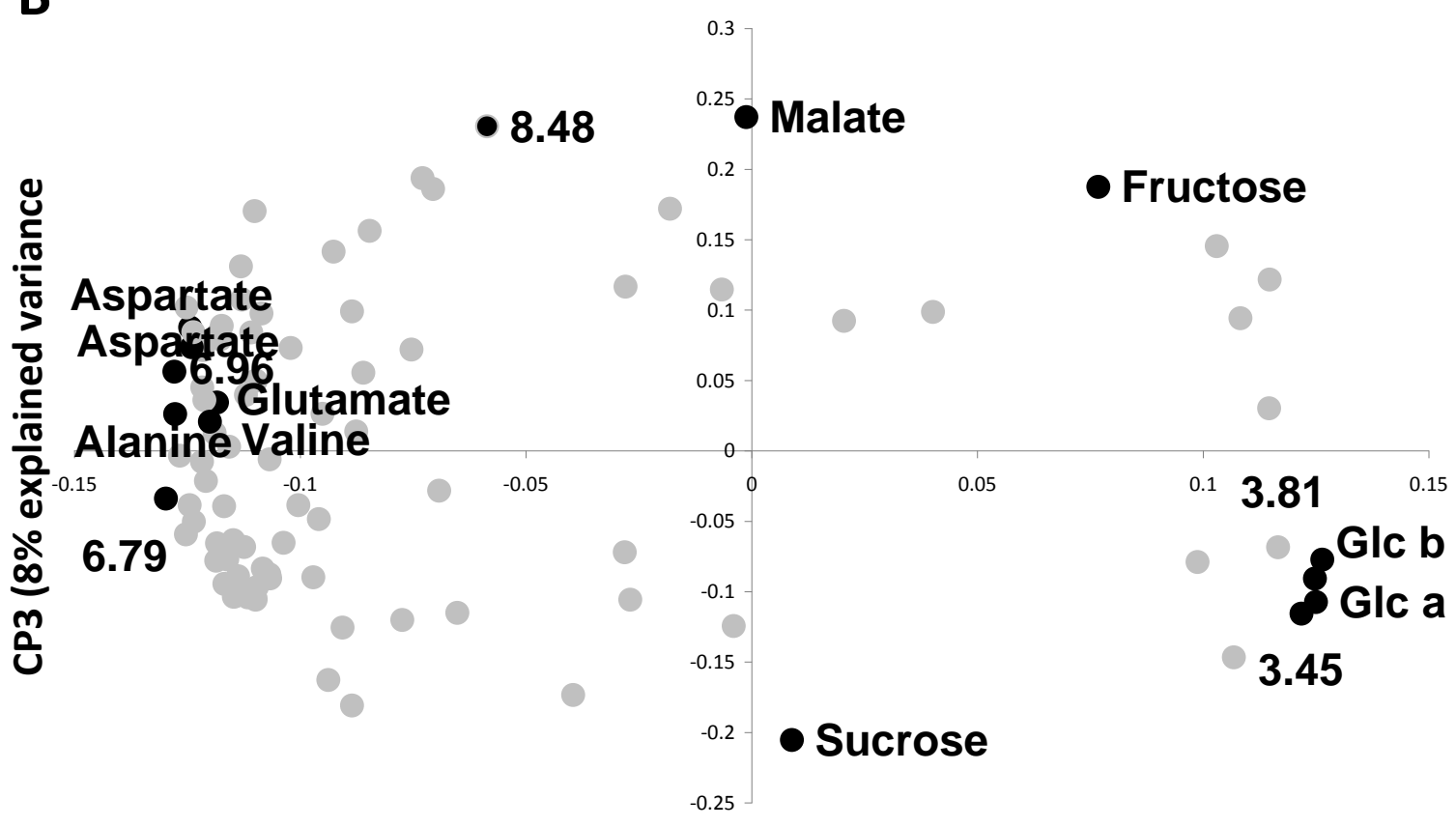

\section{CP1 (56\% explained variance)}

Figure 3. Principal component analysis (PCA) for $P_{35}$ : SIPPC2 ${ }^{\mathrm{AS}}$ samples set containing 94 variable size buckets from 1-D ${ }^{1} \mathrm{H}$-NMR fingerprinting of 16 red tomato fruit extracts $(n=2$ to 4$)$. (A) Scores plot (PC 1 vs PC 3 ) and (B) Loadings plot (PC 1 vs PC 3). Gluc a, alpha glucose; Gluc b, beta glucose.

transgenic event compared to the wild type. These results are consistent with observations on knock-out $\mathrm{m} / \mathrm{s}$ mutants in Arabidopsis. Indeed m/s mutant seedling differing relatively little from wild type (Cornah et al., 2004). They reinforce the conclusion of these authors that MLs in plant is partially dispensable for neoglucogenesis, in contrast to bacteria and fungi in which MLs is essential for gluconeogenesis from acetate or fatty acids.

The attempt to modify the metabolism of malate via PEPC or MLs pathways during ripening in tomato fruit by reverse genetics strategies (antisens or RNAi) raises 


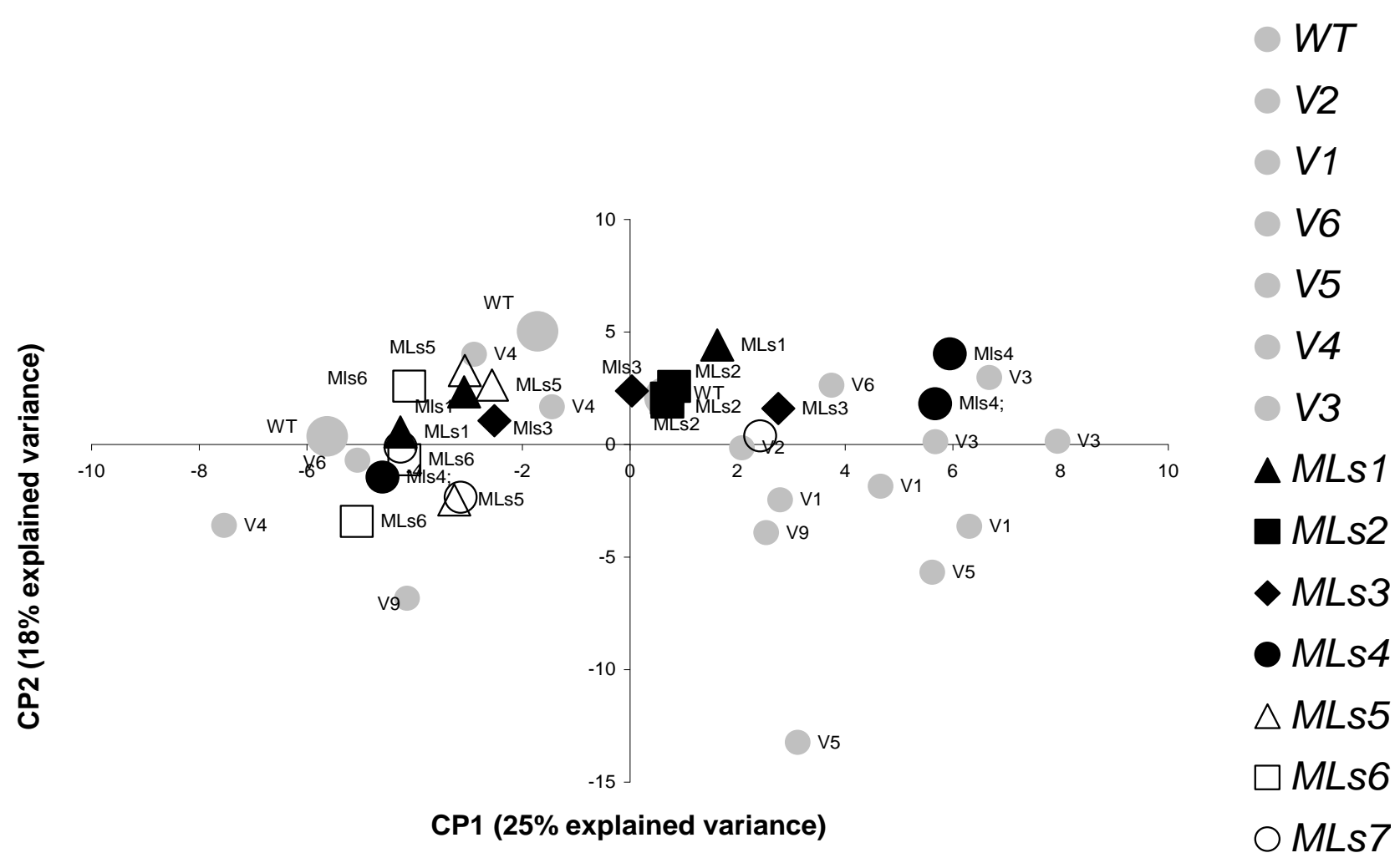

Figure 4. Principle component analysis (PCA) for $P_{35}$ : SIMLS $S^{A S}$ sample set containing 70 variable size buckets from 1-D ${ }^{1} H-N M R$ fingerprinting of 40 red tomato fruit extracts $(n=2$ to 3$)$ : wild type plants (WT, 6 independent transgenic control $(V 1$ to 6$), 7 P_{35 s}$ : $\operatorname{SIMLS}^{\mathrm{RNAi}}$ (MLs 1 to 7$)$ - scores plot (PC 1 vs PC 2).

numerous questions. The relative importance of the different pathways in the metabolism and regulation of organic acids in fruit is still poorly understood (Sweetman et al., 2009).

\section{Conclusion}

\section{A rapid and robust method for screening of transgenic plants in early generation}

The interest of this work was to propose a highthroughput procedure to analyze the metabolome of fruit with relatively few detectable, but potentially important differences in the levels of primary metabolites in transgenic plants.

The procedure described here allowed a rapid biochemical phenotyping in three fast steps:

(i) sample extraction by using a buffered methanol- $d_{4}$ extraction to avoid the drying step and ensure $\mathrm{pH}$ extract stability;

(ii) ${ }^{1} \mathrm{H}$-NMR spectrum acquisition with a relatively short relaxation delay compatible with a relative quantification analysis (a RD of $3 \mathrm{~s}$ is recommended);

(iii) data mining customized according to the tissue composition and uncontrolled chemical shift variation (variable-size bucketing).

This procedure enabled to screen about 100 samples in $36 \mathrm{~h}$ from extraction step to data mining, thus resulting in the selection of phenotype of interest among 130 transgenic lines. Applied to two sets of transgenic lines without any apparent phenotypes, this procedure allowed selecting three transgenic lines on the basis of the modification of their metabolic profile for the $P_{35 s}$ : $S I P P C 2^{A S}$ transgenic plants, and revealed that tomato fruit composition was not affected for the $\mathrm{P}_{35 \mathrm{~s}}$ : $S I M L S^{\mathrm{RNAi}}$ transgenic plants. These results allowed us to save time, because the first generations of the trans-genic plants were quickly removed from the experimental design of biological characterization.

By answering to the demand for timely information compounds, this procedure holds undeniable promise for a rapid and precocious screening of a large sample set of mutants, transgenic plants and/or growth conditions. It represents also the first step towards the identification of biological mechanisms related to transgenic or environmental events.

\section{ACKNOWLEDGEMENTS}

We thank Dr. P. Rousselle, M. Causse for the continuous support of this study and D. Jacob for developing the 
MeRy-B database; S. Maldonado for reading the text. We also wish to acknowledge the skillful technical assistance of C. Garchery and M.C. Lapize. This work was supported by MetaboP parthnership (2005 to 2007), a French program in plant genomics (GénoplanteGENE036) and by a grant from the University Tunis EI Manar (Tunisia).

\section{Abbreviations}

DW, Dry weight; NMR, nuclear magnetic resonance; PCA, principal component analysis; TSP, (Trimethylsilyl)Propionic-2,2,3,3- $d_{4}$ acid sodium Salt; EDTA, ethylenediamine tetraacetic acid disodium salt; FID, free induction decay; MS, mass spectroscopy; PEPC, phosphoenolpyruvate carboxylase; MLs, malate synthase; PEP, phosphoenolpyruvate; TCA cycle, tricarboxylic acid cycle.

\section{REFERENCES}

Allwood JW, de Vos CHR, Moing A, Deborde C, Erban A, Kopka J, Goodacre R, Hall R (2011). Plant metabolomics and its potential for systems biology research: background concepts, technology and methodology. In NW Hardy, RD Hall (eds), Plant metabolomics, Methods and Protocols. Methods in Molecular Biology 860, Springer Protocols, Humana Press. pp. 31-63.

Centeno DC, Osorio S, Nunes-Nesi A, Bertolo AL, Carneiro RT, Araújo WL, Steinhauser MC, Michalska J, Rohrmann J, Geigenberger P, Oliver SN, Stitt M, Carrari F, Rose JK, Fernie AR (2011). Malate plays a crucial role in starch metabolism, ripening, and soluble solid content of tomato fruit and affects postharvest softening. Plant Cell. 23(1): 162-184.

Choi YH, Kim HK, Hazekamp A, Erkelens C, Lefeber AWM, Verpoorte $R$ (2004). Metabolic differentiation of Cannabis sativa cultivars using ${ }^{1} \mathrm{H}-\mathrm{NMR}$ spectroscopy and principal component analysis. J. Nat. Prod. 67: 953-957.

Chollet R, Vidal J, Oleary MH (1996). Phosphoenolpyruvate carboxylase: A ubiquitous, highly regulated enzyme in plants. Annu. Rev. Plant Physiol. Plant Mol. Biol. 47: 273-298.

Cohen SA, Michaud DP (1993). Synthesis of a fluorescent derivatizing reagent, 6-aminoquinolyl-n-hydroxysuccinimidyl carbamate, and its application for the analysis of hydrolysate amino-acids via highperformance liquid-chromatography. Anal. Biochem. 211: 279-287.

Cornah JE, Germain V, Ward JL, Beale MH, Smith SM (2004). Lipid utilization, gluconeogenesis, and seedling growth in Arabidopsis mutants lacking the glyoxylate cycle enzyme malate synthase. J. Biol. Chem. 279(41): 2916-42923

Consonni R, Stocchero M, Porretta S (2009). Triple concentrated tomato paste: discrimination between Italian and chinese products. J. Agric. Food Chem. 57: 4506-4513.

Dal Cin V, Tieman DM, Tohge T, McQuinn R, de Vos RC, Osorio S, Schmelz EA, Taylor MG, Smits-Kroon MT, Schuurink RC, Haring MA, Giovannoni J, Fernie AR, Klee HJ (2011). Identification of genes in the phenylalanine metabolic pathway by ectopic expression of a MYB transcription factor in tomato fruit. Plant Cell. 23(7): 2738-2753.

Defernez M, Colquhoun IJ (2003). Factors affecting the robustness of metabolite fingerprinting using ${ }^{1} \mathrm{H}-\mathrm{NMR}$ spectra. Phytochemistry, 62 : 1009-1017.

Eastmond PJ, Graham IA (2001). Re-examining the role of the glyoxylate cycle in oilseeds. Trends Plant Sci. 6: 72-77.

del Campo G, Berregi I, Caracena R, Santos JI (2006). Quantitative analysis of malic and citric acids in fruit juices using proton nuclear magnetic resonance spectroscopy. Anal. Chim. Acta. 556: 462-468.
Enfissi EMA, Barnechec F, Ahmed I, Lichtléc C, Gerrisha C, McQuinne RP, Giovannonie JJ, Lopez-Jueza E, Bowlerc C, Bramleya PM, Fraser PD (2010). Integrative transcript and metabolite analysis of nutritionally enhanced DE-ETIOLATED1 downregulated tomato Fruit.

Fan TWM (1996). Metabolite profiling by one- and two-dimensional NMR analysis of complex mixtures. Progr. Nucl. Magn. Reson. Spectro. 28: 161-219.

Fernie AR, Trethewey RN, Krotzky AJ, Willmitzer L (2004). InnovationMetabolite profiling: from diagnostics to systems biology. Nat. Rev. Mol. Cell Biol. 5: 763-769.

Fernie AR, Klee HJ (2011). The use of natural genetic diversity in the understanding of metabolic organization and regulation. Front. Plant Sci. 2(59): 1-10.

Ferry-Dumazet H, Gil L, Deborde C, Moing A, Bernillon S, Rolin D, Nicholsky M, de Daruvar A, Jacob D (2011). MeRy-B: a web knowledgebase for the storage, visualization, analysis and annotation of plant ${ }^{\top} \mathrm{H}$-NMR metabolomic profiles, BMC Plant Biol. 11: 104-126.

Gehlen J, Panstruga R, Smets H, Merkelbach S, Kleines M, Porsch P, Fladung M, Becker I, Rademacher T, Häusler RE, Hirsch H-J (1996). Effects of altered phosphoenolpyruvate carboxylase activities on transgenic C3 plant Solanum tuberosum. Plant Mol. Biol. 32: 831 848.

Graham IA, Denby KJ, Leaver CJ (1994). Carbon catabolite repression regulates glyoxylate cycle gene-expression in cucumber. Plant Cell 6: 761-772.

Gilbert L, Alhagdow M, Nunes-Nesi A, Quemener B, Guillon F, Bouchet B, Faurobert M, Gouble B, Page D, Garcia V, Petit J, Steven R, Causse M, Fernie AR, Lahaye M, Rothan C, Baldet P (2009). GDP-dmannose 3,5-epimerase (GME) plays a key role at the intersection of ascorbate and non-cellulosic cell-wall biosynthesis in tomato. Plant $\mathrm{J}$. 60(3): 499-508.

Gromova M, Roby C (2010). Toward Arabidopsis thaliana hydrophilic metabolome: assessment of extraction methods and quantitative ${ }^{1} \mathrm{H}$ NMR. Physiol. Plant. 140: 111-127.

Guillet C, Just D, Benard N, Destrac-Irvine A, Baldet P, Hernould M, Causse M, Raymond P, Rothan C (2002). A fruit-specific phosphoenolpyruvate carboxylase is related to rapid growth of tomato fruit. Planta, 214: 717-726.

Hagel J, Facchini PJ (2008). Plant metabolomics: Analytical platforms and integration with functional genomics. Phytochem. Rev. 7: 479497.

Hagel JM, Weljie AM, Vogel HJ, Facchini PJ (2008). Quantitative 1H nuclear magnetic resonance metabolite profiling as a functional genomics platform to investigate alkaloid biosynthesis in opium poppy. Plant Physiol. 147: 1805-1821.

Hall RD, Brouwer ID, Fitzgerald MA (2008). Plant metabolomics and its potential application for human nutrition. Physiol. Plant. 132: 162-175

Hamza S, Chupeau Y (1993). Reevaluation of conditions for plantregeneration and agrobacterium-mediated transformation from tomato (Lycopersicon esculentum). J. Exp. Bot. 44: 1837-1845.

Holmes E, Foxall PJD, Nicholson JK, Neild GH, Brown SM, Beddell CR, Sweatman BC, Rahr E, Lindon JC, Spraul M, Neidig P (1994). Automatic data reduction and pattern-recognition methods for analysis of $\mathrm{H}-1$ nuclear-magnetic-resonance spectra of human urine from normal and pathological states. Anal. Biochem. 220: 284-296.

Kim HK, Choi YH, Verpoorte R (2010). NMR-based metabolomic analysis of plants. Nat. Protoc. 3: 1001-1012.

Kunst A, Draeger B, Ziegenhorn J (1984). Carbohydrates, U.V. methods with hexokinase and glucose-6-phosphate dehydrogenase, In: Bergmeyer HU (Ed). Methods in Enzymatic Analysis, 3th Edition, VI, Metabolites I., Verlag Chemie, Basel. pp. 163-172.

Law RD, Plaxton WC (1997). Regulatory phosphorylation of banana fruit phosphoenolpyruvate carboxylase by a copurifying phosphoenolpyruvate carboxylase-kinase. Eur. J. Biochem. 247: 642651.

Lebouteiller B, Gousset-Dupont A, Pierre JN, Bleton J, Tchapla A, Maucourt M, Moing A, Rolin D, Vidal J (2007). Physiological impacts of modulating phosphoenolpyruvate carboxylase levels in leaves and seeds of Arabidopsis thaliana. Plant Sci. 172: 265-272.

Le Gall G, Colquhoun IJ, Davis AL, Collins GJ, Verhoeyen ME (2003). Metabolite profiling of tomato (Lycopersicon esculentum) using ${ }^{1} \mathrm{H}$ NMR spectroscopy as a tool to detect potential unintended effects 
following a genetic modification. J. Agric. Food Chem. 51: 2447-2456.

Lindon JC, Nicholson JK (2008). Spectroscopic and statistical techniques for information recovery in metabonomics and metabolomics. Annu. Rev. Anal. Chem. 1: 45-69.

Miyao M, Fukayama H (2003). Metabolic consequences of overproduction of phosphoenolpyruvate carboxylase in C3 plants. Arch. Biochem. Biophys. 414: 197-203.

Moing $A$, Maucourt $M$, Renaud $C$, Gaudillère $M$, Brouquisse $R$, Lebouteiller B, Gousset-Dupont A, Vidal J, Granot D, DenoyesRothan B, Lerceteau-Kohler E, Rolin D (2004). Quantitative metabolic profiling by 1-dimensional ${ }^{1} \mathrm{H}$-NMR analyses: application to plant genetics and functional genomics. Funct. Plant Biol. 31: 889-902.

Moing A, Svanella L, Rolin D, Gaudillère M, Gaudillère JP, Monet R (1998). Compositional changes during the fruit development of two peach cultivars differing in juice acidity. J. Am. Soc. Hortic. Sci. 123: 770-775.

Mounet F, Moing A, Garcia V, Petit J, Maucourt M, Deborde C, Bernillon S, Le Gall G, Colquhoun I, Defernez M, Giraudel JL, Rolin D, Rothan $C$, Lemaire-Chamley M (2009). Gene and metabolite regulatory network analysis of early developing fruit tissues highlights new candidate genes for the control of tomato fruit composition and development. Plant Physiol. 149(3): 1505-1528.

Nieri B, Ciurli A, Pistelli L, Smith SM, Alpi A, De Bellis L (1997). Glyoxylate cycle enzymes in seedlings and in mature plants of tomato (Lycopersicon esculentum Mill.). Plant Sci. 129(1): 39-47.

O'Leary B, Fedosejevs ET, Hill AT, Bettridge J, Park J, Rao SK, Leach CA, Plaxton WC (2011). Tissue-specific expression and posttranslational modifications of plant- and bacterial-type phosphoenolpyruvate carboxylase isoenzymes of castor oil plant, Ricinus communis L. J. Exp. Bot. 62(15): 5485-5495.

Pua E-C, Chandramouli S, Han P, Liu P (2003). Malate synthase gene expression during fruit ripening of Cavendish banana (Musa acuminata cv. Williams). J. Exp. Bot. 54 (381): 309-316.

Rademacher T, Hausler RE, Hirsch HJ, Zhang L, Lipka V, Weier D, Kreuzaler F, Peterhansel C (2002). An engineered phosphoenolpyruvate carboxylase redirects carbon and nitrogen flow in transgenic potato plants. Plant J. 32: 25-39.

Roessner U, Willmitzer L, Fernie AR (2001). High-resolution metabolic phenotyping of genetically and environmentally diverse potato tuber systems. Identification of phenocopies. Plant Physiol. 127(3): 749764.

Ross A, Schlotterbeck G, Dieterle F, Senn H (2007). Chap 3-NMR spectroscopy techniques for application to metabonomics. In Lindon JC, Nicholson JK, Holmes E (Eds). The Handbook of Metabonomics and Metabolomics, Elsevier Inc. pp. 55-112.
Rothan C, Causse M (2007). Natural and artificially induced genetic variability in crop and model plant species for plant systems biology. EXS. 97: 21-53.

Ryan D, Robards K (2006). Analytical chemistry considerations in plant metabolomics. Sep. Purif. Rev. 35: 319-356.

Saito K, Matsuda F (2010). Metabolomics for Functional Genomics, Systems Biology, and Biotechnology. Annu. Rev. Plant Biol. 61: 463489.

Sobolev AP, Segre A, Lamanna R (2003). Proton high-field NMR study of tomato juice. Magn. Reson. Chem. 41: 237-245.

Sobolev AP, Brosio E, Gianferri R, Segre AL (2005). Metabolic profile of lettuce leaves by high-field NMR spectra. Magn. Reson. Chem. 43: 625-638.

Stitt M, ap Rees T (1978). Pathways of carbohydrate oxidation in leaves of Pisum sativum and Triticum aestivum. Phytochemistry, 17: 12511256.

Sumner LW, Mendes P, Dixon RA (2003). Plant metabolomics: largescale phytochemistry in the functional genomics era. Phytochemistry, 62: 817-836

Sweetman C, Deluc LG, Cramer GR, Ford C, Soole KL (2009). Regulation of malate metabolism in grape berry and other developing fruits. Phytochemistry 70(11-12): 1329-1344.

Trygg J, Holmes E, Lundstedt $T$ (2007). Chemometrics in metabonomics. J. Proteome Res. 6: 469-479.

Velterop JS, Vos F (2001). A rapid and inexpensive microplate assay for the enzymatic determination of glucose, fructose, sucrose, Lmalate and citrate in tomato (Lycopersicon esculentum) extracts and in orange juice. Phytochem. Anal. 12: 299-304.

Ward JL, Baker JM, Miller SJ, Deborde C, Maucourt M, Biais B, Rolin D, Moing A, Moco S, Vervoort J, Lommen A, Schafer H, Humpfer E, Beale MH (2010). An inter-laboratory comparison demonstrates that ${ }^{1} \mathrm{H}$-NMR metabolite fingerprinting is a robust technique for collaborative plant metabolomic data collection. Metabolomics, 6: 263-273.

White PJ (2002). Recent advances in fruit development and ripening: an overview. J. Exp. Bot. 53(377): 1995-2000. 